\title{
Clinical features and prognosis of life time non-smokers with severe $\alpha_{1}$-antitrypsin deficiency
}

\author{
Niels Seersholm, Axel Kok-Jensen
}

\begin{abstract}
Background-The hereditary disorder $\alpha_{1}-$ antitrypsin deficiency is characterised by development of severe emphysema at an early age with smoking being the most significant additional risk factor. The purpose of the present paper was to analyse potential risk factors other than smoking for emphysema and to estimate the prognosis of life time non-smokers.

Methods-Patients were identified through the files of the Danish $\alpha_{1}$ antitrypsin deficiency register which contains information on more than 700 persons with the condition. Many of the patients, the non-index cases, were identified from family studies.
\end{abstract}

Results-There were 75 life time nonsmokers with PiZ (27 index cases and 48 non-index cases) aged 20 years or more at entry. Twenty one subjects died during the follow up period. The Standardised Mortality Ratio (SMR) was $3.0 \quad(95 \%$ confidence intervals (CI) 1.9 to 4.6 ). There was no significant difference in SMR between males and females. The SMR was $8.8(95 \%$ CI 5.0 to 14$)$ for the index cases and $0.96(95 \%$ CI 0.3 to 2.3$)$ for the non-index cases based on five deaths. The overall mean \% predicted forced expiratory volume in one second $\left(\mathrm{FEV}_{1}\right)$ at entry was $83 \%$ with a significant difference between index cases (54\%) and non-index cases $(100 \%)(p<0.001)$. The difference in the ratio of $F E V_{1}$ to forced vital capacity (FVC) was also highly significant with values of 0.57 and 0.79 for index and non-index cases, respectively $(p<0.001)$. In the non-index group only three had an FEV $_{1} \%$ predicted of less than $70 \%$.

Conclusions-Occupational exposure to airway irritants did not have any significant influence on the development of emphysema. Only a few life time nonsmokers develop severe emphysema; most never develop pulmonary symptoms and thus remain undetected unless family members of index cases are screened. (Thorax 1998;53:265-268)

Keywords: $\alpha_{1}$-antitrypsin deficiency; smoking; mortality; lung function; prognosis

Dr $N$ Seersholm, Munkely 12, DK-2860 Søborg, Denmark.

Received 6 August 1997 Returned to authors 18 September 1997 Revised version received 20 November 1997 Accepted for publication 12 December 1997
Severe hereditary $\alpha_{1}$-antitrypsin deficiency is characterised by a reduced serum $\alpha_{1}$ antitrypsin level to about $20 \%$ of the normal level. $\alpha_{1}$-antitrypsin inhibits the activity of specific proteolytic enzymes such as trypsin, chymotrypsin, and leucocyte elastase. ${ }^{1}$ If not inactivated by $\alpha_{1}$-antitrypsin leucocyte elastase destroys lung connective tissue, particularly elastin, leading to the development of emphysema. ${ }^{23}$

Cigarette smoking is the most significant risk factor in the development of emphysema in patients with $\alpha_{1}$-antitrypsin deficiency and reduction in lung function usually begins in the third and fourth decade of life, leading to early death. ${ }^{4-6}$ However, most studies have been based on patients examined because of lung disease (index cases), and the natural history of the condition is still unknown. Studies of nonindex cases indicate that some subjects with $\alpha_{1}$-antitrypsin deficiency develop only mild emphysema, and that others never develop respiratory symptoms, particularly life time non-smokers. ${ }^{6-10}$

This is of special interest with regard to recommendations for screening for $\alpha_{1}$-antitrypsin deficiency. The rationale for identifying subjects with $\alpha_{1}$-antitrypsin deficiency through screening is to enable the subjects to avoid exposure to risk factors, particularly smoking, which has been successful in a Swedish screening programme where only $3 \%$ of adolescents with $\alpha_{1}$-antitrypsin deficiency had taken up smoking. ${ }^{11}$ The neonatal screening programme in Sweden was discontinued because it created anxiety in parents. However, a subsequent in depth analysis of the psychosocial consequences for the families revealed a generally favourable attitude towards screening. ${ }^{12}$

The aim of the present study of life time non-smokers with $\alpha_{1}$-antitrypsin deficiency was to analyse additional risk factors for emphysema, and to estimate the degree of respiratory symptoms and prognosis with particular emphasis on the large number of non-index cases.

\section{Methods}

Patients were identified from the files of the Danish $\alpha_{1}$-antitrypsin deficiency register. Since 1978 patients with $\alpha_{1}$-antitrypsin deficiency have been registered by physicians throughout Denmark. Once a patient is registered a family record is obtained and members at risk of having a $\mathrm{Z}$ gene are offered an examination of their Pi type. In this way a large number of family members who do not necessarily have respiratory symptoms have been identified-the nonindex cases.

Determination of $\alpha_{1}$-antitrypsin Pi type was usually verified by the Department of Clinical Chemistry at Bispebjerg Hospital by isoelectric focusing as described by Fagerhol and Cox. ${ }^{13}$ If phenotyping had not been performed, the patients were assumed to have genotype PiZZ or PiZ0 if their $\alpha_{1}$-antitrypsin serum level was less than $12 \mu \mathrm{mol} / 1$. 
In the register smoking status is defined as follows. A smoker is a person who has smoked at least 20 packs of cigarettes or at least one cigarette per day for at least one year in a life time, ${ }^{14}$ an ex-smoker is a person who has abstained from smoking for at least three months, and a never smoker is a person who is not a smoker or an ex-smoker.

Data on respiratory symptoms were obtained from a Danish translation of the BMRC questionnaire ${ }^{15}$ submitted to all patients alive in August 1991 and consecutively on registration.

For the index cases lung function measurements (spirometry) were reported by the referring physician. When the non-index cases were identified they were encouraged to contact their general practitioner for measurement of lung function. Measurements were performed in accordance with European recommendations. ${ }^{16}$ Predicted values of forced expiratory volume in one second $\left(\mathrm{FEV}_{1}\right)$ were calculated according to European reference tables. ${ }^{16}$ For this study the first spirometric measurement after the patient entered the register was used.

Information on date of death or emigration was obtained from the Danish Central Population Register which was established in 1968 and holds information on all Danish citizens. Death certificates providing information on cause of death were obtained from the Danish National Board of Health.

Patients eligible for the present study were life time non-smokers identified as phenotype $\mathrm{Z}$ or with a serum $\alpha_{1}$-antitrypsin level of less than $12 \mu \mathrm{mol} / 1$ who were aged over 20 years at entry to the register.

\section{STATISTICAL ANALYSIS}

The period of follow up for survival calculation was taken from the date of entry into the register to the date of death, emigration, or 31 December 1996, whichever came first. ${ }^{4}$ Age, date, and sex specific standardised mortality rates (SMR) were calculated from the Danish reference tables published every year. ${ }^{17}$ The $t$ test was used to evaluate differences in age, $\mathrm{FEV}_{1}$, and follow up time and dichotomous variables were evaluated by Fisher's exact test.

\section{Results}

The register contained 75 subjects with a $\mathrm{PiZ}$ genotype who had never smoked and were 20 years or older at entry. Twenty seven were index cases and 48 were non-index cases (table 1). There were $39 \%$ men in the study population with $44 \%$ in the index group and $35 \%$ in the non-index group $(\mathrm{p}=0.44)$. The mean follow up time was 8.7 years (range 3 months to 19 years), 5.4 years ( 3 months to 16.6 years) for the index cases and 10.6 years (1.2-19 years) for the non-index cases $(\mathrm{p}<0.001)$. The overall mean age at entry was 50.0 years (range $21.4-85.1$ years). The index cases were significantly older at entry than the non-index cases with mean ages at entry of 56.2 (range 27.2-82.6) years and 46.5 (range $21.4-85.1)$ years, respectively $(\mathrm{p}<0.01)$. The overall mean serum $\alpha_{1}$-antitrypsin level was
Table 1 Mean (SD) demographic data of the study population

\begin{tabular}{lcc}
\hline & Index cases & $\begin{array}{l}\text { Non-index } \\
\text { cases }\end{array}$ \\
\hline No. & $27(36 \%)$ & $48(64 \%)$ \\
Deaths & $16(59 \%)$ & $5(8.3 \%)$ \\
$\mathrm{M} / \mathrm{F}$ & $12 / 15$ & $17 / 31$ \\
Age at diagnosis (years) & $56.2(12.7)$ & $46.5(13.9)$ \\
Follow up (years) & $5.4(3.9)$ & $10.6(5.8)$ \\
$\alpha_{1}$-antitrypsin $(\mu \mathrm{mol} / \mathrm{l})$ & $8.2(3.0)$ & $8.1(2.8)$ \\
\hline
\end{tabular}

$8.5 \mu \mathrm{mol} / 1$ with no significant difference between the index and the non-index groups.

During the follow up period 21 subjects died, 16 in the index group and five in the nonindex group. The median age at death was 66.9 years. The index cases were significantly younger than the non-index cases with median ages at death of 66.5 and 71.1 years, respectively. In table 2 the cause of death, sex, and age at death are shown; most of the index cases died of pulmonary emphysema whereas only one of the non-index cases died of this disease. The SMR for the whole study population was 3.0 (95\% confidence intervals (CI) 1.9 to 4.6 ). There was no significant difference in SMR between men and women with values of 3.4 (95\% CI 1.1 to 7.8 ) and 2.9 (95\% CI 1.7 to 4.7), respectively. The SMR was 8.8 (95\% CI 5.0 to 14$)$ for the index cases and $0.96(95 \% \mathrm{CI}$ 0.3 to 2.3) for the non-index cases .

Spirometric data were missing for eight nonindex cases but these did not differ significantly in age at entry, follow up time, or sex from the cases for whom spirometric data were available, although they tended to be older at entry. The initial $\mathrm{FEV}_{1} \%$ predicted and $\mathrm{FEV}_{1} / \mathrm{FVC}$ ratio for index cases and non-index cases stratified for age at entry are shown in table 3. The overall mean $\mathrm{FEV}_{1} \%$ predicted was $83 \%$ with a significant difference between index cases $(54 \%)$ and non-index cases $(100 \%$; $\mathrm{p}<0.001)$. The difference in the $\mathrm{FEV}_{1} / \mathrm{FVC}$ ratio was also highly significant with values of 0.57 and 0.79 for index cases and non-index cases, respectively $(p<0.001)$. In the index group $\mathrm{FEV}_{1} \%$ predicted for the subjects under

Table 2 Cause of death by mode of ascertainment

\begin{tabular}{ccl}
\hline Sex & $\begin{array}{c}\text { Age at } \\
\text { death }\end{array}$ & Cause of death \\
\hline Index & & \\
$\mathrm{F}$ & 72 & Unknown \\
$\mathrm{F}$ & 77 & Ischaemic heart disease \\
$\mathrm{M}$ & 50 & Pulmonary emphysema \\
$\mathrm{F}$ & 50 & Pulmonary emphysema \\
$\mathrm{M}$ & 56 & Pulmonary emphysema \\
$\mathrm{M}$ & 58 & Pulmonary emphysema \\
$\mathrm{M}$ & 62 & Pulmonary emphysema/diverticulitis \\
$\mathrm{M}$ & 65 & Pulmonary emphysema \\
$\mathrm{F}$ & 65 & Pulmonary emphysema \\
$\mathrm{F}$ & 66 & Pulmonary emphysema \\
$\mathrm{F}$ & 66 & Pulmonary emphysema \\
$\mathrm{F}$ & 68 & Pulmonary emphysema \\
$\mathrm{F}$ & 71 & Pulmonary emphysema/pneumothorax \\
$\mathrm{F}$ & 75 & Pulmonary emphysema \\
$\mathrm{F}$ & 79 & Pulmonary emphysema \\
$\mathrm{F}$ & 83 & Pulmonary embolism \\
$\mathrm{F}$ & & \\
$\mathrm{F}$ & 53 & Lung cancer \\
$\mathrm{F}$ & 66 & Intra-abdominal cancer \\
$\mathrm{F}$ & 71 & Intra-abdominal bleeding \\
$\mathrm{F}$ & 74 & Pulmonary emphysema/pneumonia \\
$\mathrm{F}$ & 89 & Congestive heart failure \\
\hline
\end{tabular}


Table 3 Mean (SD) $F E V_{1} \%$ predicted and $F E V_{1} / F V C$ of index and non-index cases stratified by age at entry

\begin{tabular}{|c|c|c|c|}
\hline & Index cases & Non-index cases & $\begin{array}{l}p \text { value } \\
\text { (t test) }\end{array}$ \\
\hline All age groups & $\mathrm{n}=27$ & $\mathrm{n}=40$ & \\
\hline $\mathrm{FEV}_{1} \%$ predicted & $54(25)$ & $100(21)$ & $<0.001$ \\
\hline $\mathrm{FEV}_{1} / \mathrm{FVC}$ & $0.57(0.18)$ & $0.79(0.13)$ & $<0.001$ \\
\hline $\mathrm{N}(\%)$ with $\mathrm{FEV}_{1} \%$ pred $\leqslant 70 \%$ & $20(74 \%)$ & $3(8 \%)$ & $<0.001$ \\
\hline Age at entry $<50$ years & $\mathrm{n}=8$ & $\mathrm{n}=26$ & \\
\hline $\mathrm{FEV}_{1} \%$ predicted & $33(24)$ & $98(18)$ & $<0.001$ \\
\hline $\mathrm{FEV}_{1} / \mathrm{FVC}$ & $0.42(0.16)$ & $0.80(0.12)$ & $<0.001$ \\
\hline $\mathrm{N}(\%)$ with $\mathrm{FEV}_{1} \%$ pred $\leqslant 70 \%$ & $4(50 \%)$ & $2(8 \%)$ & $<0.001$ \\
\hline Age at entry $\geqslant 50$ years & $\mathrm{n}=19$ & $\mathrm{n}=14$ & \\
\hline FEV \% predicted & 47 (19) & $97(23)$ & $<0.001$ \\
\hline $\mathrm{FEV}_{1} / \mathrm{FVC}$ & $0.58(0.19)$ & $0.78(0.14)$ & $<0.001$ \\
\hline $\mathrm{N}(\%)$ with $\mathrm{FEV}_{1} \%$ pred $\leqslant 70 \%$ & $16(84 \%)$ & $1(7 \%)$ & $<0.001$ \\
\hline
\end{tabular}

Table 4 Respiratory symptoms as responded to the BMRC questionnaire

\begin{tabular}{llll}
\hline & \multicolumn{2}{l}{$\begin{array}{l}\text { Percentage of affirmative } \\
\text { responses }\end{array}$} & \\
\cline { 2 - 3 } & $\begin{array}{l}\text { Index cases } \\
(n=17)\end{array}$ & $\begin{array}{l}\text { Non-index } \\
\text { cases }(n=44)\end{array}$ & $\begin{array}{l}\text { palue } \\
\text { (Fisher's exact } \\
\text { test })\end{array}$ \\
\hline Cough & $53 \%$ & $12 \%$ & 0.002 \\
Cough for three consecutive months per year & $47 \%$ & $14 \%$ & 0.01 \\
Phlegm & $41 \%$ & $11 \%$ & 0.03 \\
Phlegm for three consecutive months per year & $35 \%$ & $11 \%$ & 0.06 \\
Shortness of breath & $88 \%$ & $46 \%$ & 0.003 \\
Attacks of wheeziness & $59 \%$ & $27 \%$ & 0.04 \\
Asthma & $35 \%$ & $9 \%$ & 0.02 \\
Pneumonia & $82 \%$ & $34 \%$ & 0.001 \\
\hline
\end{tabular}

50 years at entry was 33\% compared with $47 \%$ for the subjects over 50 years, but this difference was not significant. In the non-index group only three subjects had $\mathrm{FEV}_{1} \%$ predicted under $70 \%$ and the oldest person with normal lung function was 67 years, which was also the age of the oldest non-index subject for whom spirometric data were available.

The pulmonary symptoms obtained from answers to the questionnaire for index and non-index cases are shown separately in table 4. Of the 64 eligible subjects (alive in 1991 or later when the questionnaire was submitted), $61(95 \%)$ returned the questionnaire including $17(94 \%)$ index cases and $44(96 \%)$ non-index cases. The index cases had significantly more respiratory symptoms in terms of cough, phlegm, and shortness of breath than the nonindex cases. However, of the non-index cases $46 \%$ suffered from shortness of breath when hurrying on the level or walking up a slight hill and $27 \%$ complained of wheeziness. To the question "have you ever had asthma?" $35 \%$ of the index cases and $9 \%$ of the non-index cases answered yes $(p<0.05)$. When asked whether they had pneumonia $82 \%$ in the index group and $34 \%$ in the non-index group responded affirmatively $(p<0.01)$.

To questions on occupational exposure to dust or chemical agents $35 \%$ of the index cases and $30 \%$ of the non-index cases answered yes to exposure to dust $(\mathrm{p}=0.8)$, and $24 \%$ and $14 \%$, respectively, answered yes to exposure to chemical agents or irritants $(\mathrm{p}=0.4)$.

\section{Discussion}

In studies of the natural history of $\alpha_{1}$ antitrypsin deficiency ascertainment bias has been a major problem. Subjects with severe respiratory symptoms who are mainly smokers have therefore had a better chance of being included in epidemiological studies, resulting in too pessimistic a prognosis. With the inclusion of more non-index cases in epidemiological studies the variability of lung function impairment and mortality have been recognised, and in previous studies of never smoking non-index cases we found a life expectancy no different from that of the normal Danish population ${ }^{6}$ and an estimated annual decline in $\mathrm{FEV}_{1}$ of $36 \mathrm{ml} /$ year which is within normal limits. ${ }^{10}$

Studies of life time non-smokers with $\alpha_{1}$-antitrypsin deficiency are sparse and comprise mostly index cases. ${ }^{269}$ The present study of never smokers includes a large proportion of non-index cases found through family studies. We found that the non-index cases did not have increased mortality and very few of them had impaired lung function. The index cases had a tenfold increase in mortality, critically reduced lung function, and severe respiratory symptoms.

Alpha $_{1}$-antitrypsin deficiency is a good example of the impact of environmental factors on the phenotype of a genetic disease. However, in the present study the environmental factor, smoking - which is the strongest risk factor for emphysema described so far-was absent. However, some of the subjects had developed severe emphysema. These patients may have been exposed to other factors that contribute to the development of emphysema-for example, other environmental factors such as passive smoking or occupational exposure to dust and chemical fumes, potential predisposing diseases such as asthma or respiratory infections, or other genetic factors.

We did not find any significantly increased exposure to dust and fumes among the index cases. This finding is based on only a few subjects, and even if there was a significant difference it could be due to recall bias. Unfortunately we have no information on the exposure to passive smoking, nor has it been possible to assess whether the index cases were more exposed to environmental pollution. One other study failed to show any association between exposure to dust, chemical fumes, and passive smoking, ${ }^{7}$ but in a recent study of never smokers with $\alpha_{1}$-antitrypsin deficiency it was suggested that occupational exposure to airway irritants was an independent additional risk factor. ${ }^{18}$

Significantly more index cases than nonindex cases responded affirmatively to the questions concerning asthma and wheeziness. This has also been found by other authors $^{471819}$ and the question is whether symptoms are part of emphysema or whether asthma is present together with emphysema in subjects with $\alpha_{1}$-antitrypsin deficiency. It is well known that emphysema in PiZ subjects may be misinterpreted by doctors and patients as asthma before the PiZ diagnosis is established ${ }^{20}$ and therefore the patient will answer affirmatively to the question on asthma. Several studies have shown that there is an increased number of neutrophils in the bronchoalveolar 
lavage fluid from asthma patients, and these neutrophils may result in lung tissue damage and development of emphysema in patients with $\alpha_{1}$-antitrypsin deficiency. With our present knowledge it is impossible to assess whether the symptoms of asthma are part of emphysema or whether asthma causes emphysema in patients with $\alpha_{1}$-antitrypsin deficiency.

A significantly larger proportion of the index cases answered positively to the question of pneumonia, indicating that respiratory infections may contribute to the development of emphysema. However, there is also the dilemma of whether pneumonia develops more often in patients with advanced emphysema or whether frequent attacks of pneumonia result in emphysema in patients with $\alpha_{1}$-antitrypsin deficiency. There is no doubt that patients with severe emphysema or chronic obstructive pulmonary disease (COPD) often have pneumonia and we think this is the reason for the higher proportion of affirmative responses among the index cases. However, it has been suggested that childhood respiratory infections lead to the development of COPD. ${ }^{21} \mathrm{~A}$ prospective study of 103 Swedish children with $\alpha_{1}$-antitrypsin deficiency showed that they had normal lung function when they reached adulthood, indicating that childhood respiratory infections are not a major factor for emphysema. $^{22}$

Can other genetic factors contribute to the development of respiratory disease in these subjects? Silverman and colleagues have done extensive work on this matter and have suggested that there might be other genetic factors involved, but their studies were limited by a small number of families. ${ }^{23}{ }^{24}$ It would be interesting to compare the lung function of the parents of index cases with that of the parents of non-index cases. Unfortunately only a few of the parents have undergone spirometric testing and such a comparison was not possible. From our data we are not able to determine whether environmental factors or other genetic factors are responsible for the advanced emphysema among the index cases.

It is important to emphasise that the non-index cases did not have an excess mortality and had, on average, normal lung function, and most never smokers with $\alpha_{1}$ antitrypsin deficiency live a normal life without respiratory symptoms.

In view of the good prognosis of never smokers, insurance companies should reconsider their policy and not deny life insurance to life time non-smokers with $\alpha_{1}$-antitrypsin deficiency identified through screening. Furthermore, it is important to identify $\alpha_{1}$-antitrypsin deficiency homozygotes early with regard to counselling to avoid smoking and, although the evidence for other environmental factors in the development of emphysema is weak, exposure to high degree of airway irritants should be avoided. We will encourage screening of family members of index cases and, depending on the frequency of the $\mathrm{Z}$ gene in the population, it might be worthwhile to screen all adults at the age of $15-20$ years which is the age at which people usually start smoking. Once identified, individuals with $\alpha_{1}$-antitrypsin deficiency should be followed with spirometric testing every 3-5 years in order to detect those with an accelerated decline in lung function.

1 Brantly M, Nukiwa T, Crystal RG. Molecular basis of alpha-1-antitrypsin deficiency. Am F Med 1988;84:13-31. 2 Eriksson S. Studies in alpha 1-antitrypsin deficiency. Acta Med Scand 1965;S432:1-85.

3 Tobin MJ, Cook PJ, Hutchison DC. Alpha 1-antitrypsin deficiency: the clinical and physiological features of pulmonary emphysema in subjects homozygous for Pi type $\mathrm{Z}$. A survey by the British Thoracic Association. Br $\mathcal{F}$ Dis Chest 1983;77:14-27.

4 Larsson C. Natural history and life expectancy in severe alpha 1-antitrypsin deficiency, PiZ. Acta Med Scand 1978; 204:345-51.

5 Janus ED, Phillips NT, Carrell RW. Smoking, lung function, and alpha 1-antitrypsin deficiency. Lancet 1985;i:152-4.

6 Seersholm N, Kok-Jensen A, Dirksen A. Survival of patients with severe alpha 1-antitrypsin deficiency with special reference to non-index cases. Thorax 1994;49:695-8.

7 Silverman EK, Pierce JA, Province MA, et al. Variability of pulmonary function in alpha-1-antitrypsin deficiency: clinical correlates. Ann Intern Med 1989;111:982-91.

8 Poller W, Faber JP, Olek K. Highly variable clinical course in severe alpha 1-antitrypsin deficiency: use of polymerase chain reaction for the detection of rare deficiency alleles. Klin Wochenschr 1990;68:857-63.

9 Black LF, Kueppers F. Alpha-1-antitrypsin deficiency in nonsmokers. Am Rev Respir Dis 1978;117:421-8.

10 Seersholm N, Kok-Jensen A, Dirksen A. Decline in FEV among patients with severe hereditary alpha-1-antitrypsin deficiency type PiZ. Am f Respir Crit Care Med 1995;152: 1922-5.

11 Sveger T, Thelin T, McNeil TF. Young adults with alpha-1antitrypsin deficiency identified neonatally: their health, knowledge about and adaptation to the high-risk condition. Acta Paediatr 1997;86:37-40.

12 McNeil TF, Sveger T, Thelin T. Psychosocial effects of screening for somatic risk: the Swedish alpha-1-antitrypsin experience. Thorax 1988;43:505-7.

13 Fagerhol MK, Cox DW. The Pi polymorphism. Genetic, biochemical and clinical aspects of human alpha 1-antitrypsin. Adv Human Genet 1981;11:1-62.

14 American Thoracic Society. Statement by the Committee on Standards for Epidemiology Surveys on Chronic Respiratory Disease of the American Thoracic Society. New York: National Tuberculosis and Respiratory Disease York: National Tuberch

15 Medical Research Council Committee on the Aetiology of Chronic Bronchitis. Standardized questionnaires on respiratory symptoms. BMF 1960;2:1665.

16 Quanjer PH. Standardized lung function testing. Eur Respir f 1993;6(Suppl 16):3-102.

17 Danmarks Statistik (National Danish Statistics Bureau). Statistical yearbook. 1990: 94.

18 Piitulainen E, Tornling G, Eriksson S. Effect of age and occupational exposure to airway irritants on lung function in non-smoking individuals with $\alpha_{1}$-antitrypsin deficiency (PiZZ). Thorax 1997;52:244-8.

19 Brantly ML, Paul LD, Miller BH, et al. Clinical features and history of the destructive lung disease associated with alpha-1-antitrypsin deficiency of adults with pulmonary alpha-1-antitrypsin deficiency of adults with p
symptoms. Am Rev Respir Dis 1988;138:327-36.

20 Stoller JK, Smith P, Yang P, et al. Physical and social impact of alpha 1-antitrypsin deficiency: results of a survey. Cleve Clin F Med 1994;61:461-7.

21 Burrows B, Knudson RJ, Lebowitz MD. The relationship of childhood respiratory illness to adult obstructive airway disease. Am Rev Respir Dis 1977;115:751-60.

22 Sveger T, Piitulainen E, Arborelius M Jr. Clinical features and lung function in 18-year-old adolescents with alpha 1-antitrypsin deficiency. Acta Paediatr 1995;84:815-6.

23 Silverman EK, Province MA, Campbell EJ, et al. Biochemical intermediates in alpha 1-antitrypsin deficiency: residual family resemblance for total alpha 1-antitrypsin, oxidized alpha 1-antitrypsin, and immunoglobulin E after adjustment for the effect of the Pi locus. Genet Epidemiol 1990;7: ment for

24 Silverman EK, Province MA, Campbell EJ, et al. Family study of alpha 1-antitrypsin deficiency: effects of cigarette smoking, measured genotype, and their interaction on pulmonary function and biochemical traits. Genet Epidemiol 1992;9:317-31. 


\section{Case reports}

\section{Commentary}

\author{
David M Hansell
}

The common feature of the reports by Franco et $a l^{1}$ and Oliver $e t a l^{2}$ is the use of spiral (or volumetric) computed tomography to demonstrate features which would not be readily identifiable on conventional computed tomographic (CT) scanning. The advantages of spiral CT over conventional CT scanning are twofold: increased speed of data acquisition and volumetric (rather than slice by slice) data acquisition. The attribute of speed means that most thoracic examinations can be performed within a single breath hold and the timing of intravenous contrast administration can be precisely tailored, thus allowing reproducible enhancement of any desired part of the vasculature - for example, the pulmonary arteries in cases of suspected pulmonary embolism. Because an entire volume of data is acquired (with almost equal spatial resolution in the three axes) it is possible to reconstruct images in any plane, including threedimensional (3-D) reconstructions. ${ }^{3}$ Most examinations acquired with spiral CT scanning are presented as a series of transaxial slices, reflecting the traditional presentation of conventional $\mathrm{CT}$ images.

In the report by Franco et al the clarity with which the anomalous arteries feeding the sequestrated lung are shown on the 3-D reconstructions is striking. In the past a separate preoperative examination (either aortography or possibly magnetic resonance angiography) to identify the vascular supply would have been regarded as mandatory. Other imaging tests such as radionuclide scintigraphy or ultrasound may answer specific questions in cases of pulmonary sequestration, but the wealth of information now available from a single spiral CT examination is remarkable. Quite apart from their aesthetic appeal, the main benefit of these readily produced 3-D reconstructions is an easy appreciation of what can be complex anatomy. Nevertheless, claims for the increased diagnostic gain from these 3-D reconstructions should not be too extravagant: the anomalous vessels would be identifiable on images presented in the standard transaxial format, although without such immediacy. Furthermore, demonstration of the venous drainage into the pulmonary circulation (for the classic intralobar sequestrations) may not be so readily obtained with a single spiral CT examination. However, the ability to extract so much information from a spiral CT examination represents a substantial advance on conventional CT scanning.
Spiral CT pulmonary angiography is an effective way of demonstrating pulmonary embolism in segmental and larger arteries. ${ }^{4}$ The basic sign of a filling defect within a well opacified pulmonary artery is straightforward enough. The case report by Oliver et al highlights the fact that there may be ancillary signs of pulmonary embolism on spiral CT scanning-in this case shift of the interventricular septum - which corroborates the diagnosis and, more controversially, provides prognostic information. Shift of the interventricular septum and other signs of right ventricular dysfunction are readily demonstrated on echocardiography, but in cases of suspected pulmonary embolism echocardiography does not provide the breadth of information of a spiral CT examination. For example, additional signs of pulmonary embolism, including a mosaic perfusion pattern of the lung parenchyma and radiographically cryptic pleural effusions or small pulmonary infarcts, can be readily picked up on spiral CT scanning. Conversely, because spiral CT scanning provides the "big picture", an alternative diagnosis may be shown by spiral CT scanning in up to one third of patients investigated for suspected pulmonary embolism. ${ }^{5}$

The application of image processing to volumetric spiral CT data can be broadly divided into graphic 3-D realisations-for example, virtual reality bronchoscopy ${ }^{6}$ - and the rendering of data so that it is suitable for quantitative analysis. However, progress towards routine volumetric (3-D) depictions of spiral CT data is likely to be slow. ${ }^{7}$ Even at this early stage of development it is possible to extract very precise volumetric measures of abnormal lung; the most obvious application is in the quantification of low attenuation lung (corresponding to emphysema) on inspiratory and expiratory spiral CT scans. Early results have shown remarkably good correlation between the extent of low attenuation lung derived from 3-D reconstructions of the lungs with functional indices of air flow obstruction and air trapping. ${ }^{8}$ With this new technique the entire lungs are evaluated, unlike the conventional "density mask" approach which can be applied only to individual CT sections, (which introduces problems with sampling). With the powerful combination of volumetric data from spiral CT scanning and advanced image processing, the excitement has only just begun.

1 Franco J, Aliaga R, Domingo ML, et al. Diagnosis of pulmonary sequestration by spiral CT angiography. Thorax 1998;53:1089-92.

2 Oliver TB, Reid JH, Murchison JT. Interventricular septal shift due to massive pulmonary embolism shown by CT pulmonary angiography: an old sign revisited. Thorax 1998;53:1092-4.

3 Remy J, Remy-Jardin M, Artaud D, et al. Multiplanar and three-dimensional reconstruction techniques in CT: impact on chest diseases. Eur Radiol 1998;8:335-51. 
4 Remy-Jardin M, Remy J, Deschildre F, et al. Diagnosis of pulmonary embolism with spiral CT: comparison with pulmonary angiography and scintigraphy. Radiology 1996;200:699706 .

5 Cross JJ, Kemp PM, Walsh CG, et al. A randomized trial of spiral CT and ventilation perfusion scintigraphy for the diagnosis of pulmonary embolism. Clin Radiol 1998;53: $177-82$.

6 Chinn RJS, Mellor J, Yang GZ, et al. Three dimensional computed tomography bronchoscopy using clinical datasets: a comparison with fibreoptic bronchoscopy. Clin Radiol 1997:52:837-41.

7 Rubin GD, Napel S, Leung AN. Volumetric analysis of volumetric data: achieving a paradigm shift. Radiology 1996;200:312-7.

8 Mergo PJ, Williams WF, Gonzalez-Rothi R, et al. Three-dimensional volumetric assessment of abnormally low attenuation of the lung from routine helical CT: inspiratory and expiratory quantification. AfR 1998;170: 1355-60.

\section{Thorax 1998;53:1089-1092 Diagnosis of pulmonary sequestration by spiral CT angiography} José Franco, Roberto Aliaga, María L
Domingo, Pedro Plaza

\begin{abstract}
The diagnosis of pulmonary sequestration traditionally requires arteriography to identify abnormal systemic vessels feeding the abnormal portion of the lung. Non-invasive imaging techniques have recently been used to replace arteriography. Conventional computed tomographic (CT) scanning is, however, at a disadvantage because of its inability to obtain multiplanar images. The combination of slip ring CT scanning and computerised three-dimensional reconstruction (spiral CT angiography) can be used to visualise the anatomical detail of a wide range of vessels within the lung. Four cases of pulmonary sequestration are reported which were successfully diagnosed using spiral CT angiography. Spiral CT scanning allows simultaneous imaging of anomalous vessels and lung parenchyma in a single examination and is particularly useful in the diagnosis and assessment of pulmonary sequestration.

(Thorax 1998;53:1089-1092)
\end{abstract}

Department of

Pneumology

J Franco

P Plaza

Department of Radiology

R Aliaga

M L Domingo

University Hospital Dr. Peset, Valencia, Spain

Correspondence to: Dr J Franco, Centro de Especialidades de Alzira, Hort dels Frares 60 E-46600 Alzira, Valencia, Spain.

Received 23 February 1998 Returned to author 13 May 1998 Revised manuscript received 8 July 1998

Accepted for publication 20 August 1998
Keywords: pulmonary sequestration; spiral computed tomography

Pulmonary sequestration is a rare congenital pulmonary disorder defined as an area of dysplastic and non-functioning pulmonary tissue with an anomalous systemic blood supply. ${ }^{1}$ It has been classically described in two formsintralobar sequestrations located within the visceral pleura and surrounded by normal lung, and extralobar sequestrations which have a separate pleural covering. Both types are supplied with blood from the aorta or its branches. The venous return of the intralobar sequestration is usually via the pulmonary veins while extralobar sequestrations generally have systemic venous drainage. Nevertheless, many variations and combinations of these classical patterns have been described. ${ }^{2}$

Traditionally, the diagnosis of pulmonary sequestration requires arteriography to identify abnormal systemic vessels feeding the abnor- mal portion of the lung. More recently, other procedures have been advocated as a less invasive means of identifying the anomalous artery. Although conventional computed tomographic (CT) scanning can show both abnormal lung parenchyma and the systemic arterial supply, ${ }^{3}$ it lacks the multiplanar images which limits its usefulness in the diagnosis of sequestration. With the advent of helical technology, spiral CT angiography is able to delineate the aorta and its branches. The role of CT scanning in evaluating suspected pulmonary sequestration should therefore be re-evaluated. ${ }^{4}$

In this report we describe the use of spiral CT angiography to image the aberrant systemic artery in four cases of pulmonary sequestration.

\section{Methods}

We performed four CT angiography studies with a PQ2000S helical scanner (Picker International Inc, Highlands Heights, Ohio, USA). Spiral volumetric CT scanning was performed with $4 \mathrm{~mm}$ slide thickness, $4 \mathrm{~mm}$ table speed, $3 \mathrm{~mm}$ reconstruction index, and smooth reconstruction algorithm. A non-ionic contrast medium $(120 \mathrm{ml}$, iodine $300 \mathrm{mg} / \mathrm{ml}$ ) was administered at a rate of $3 \mathrm{ml} / \mathrm{s}$ via the antecubital vein.
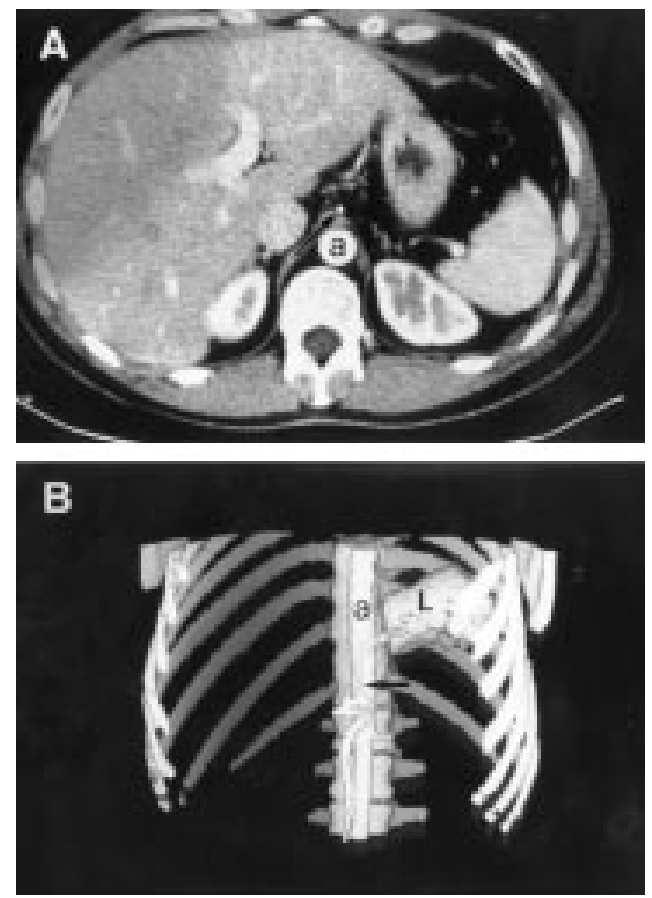

Figure 1 Spiral CT scan of case 1. (A) Contrast enhanced CT axial image showing the small aberrant artery (arrow) adjacent to the upper abdominal aorta (a). (B) Anterior view of helical CT angiogram. The anomalous artery (arrow) feeding the pulmonary lesion (L) arises from the coeliac axis. 

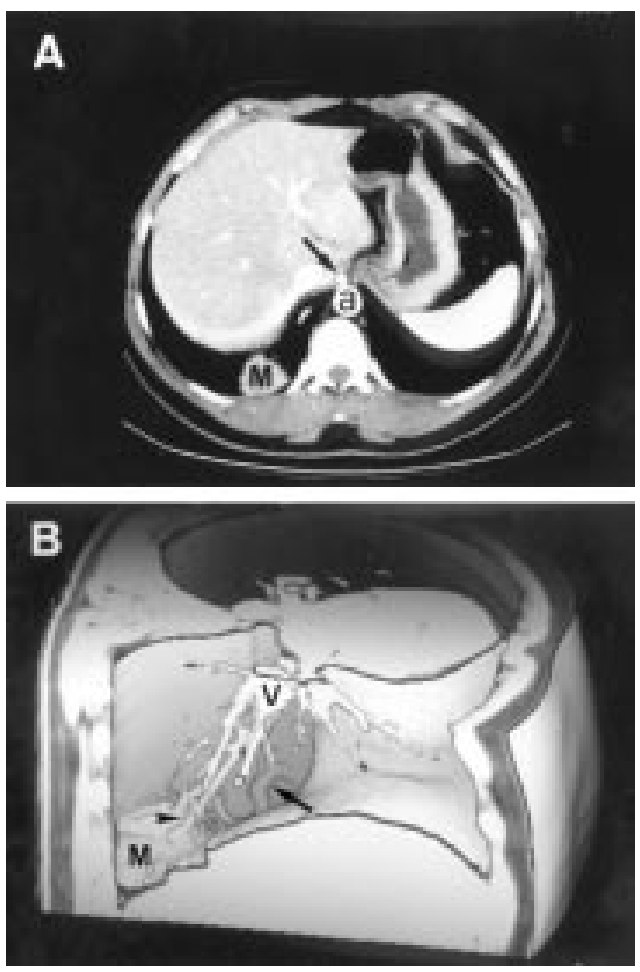

Figure 2 Spiral CT scan of case 2. (A) Contrast enhanced $C T$ axial image showing the pulmonary mass (M) supplied by an anomalous systemic artery (arrow) arising from the upper abdominal aorta (a). (B) Right view of helical CT angiogram showing the course of the arterial vessel (arrow) to the pulmonary mass $(M)$. Note the venous drainage (arrowhead) to the pulmonary veins $(V)$.

A 25 second scan delay was used in order to optimise contrast in the systemic arterial phase of the study. Three-dimensional reconstruction (3D) was performed with a Voxel Q work station using a shaded surface display (SSD) program with segmentation option.

\section{Case reports}

CASE 1

A 32 year old man with a 34 pack-year history of cigarette smoking who still smoked two packs a day was admitted to the smoking cessation programme at our hospital. There was a history of pneumonia at the age of 14. A chest radiograph showed localised air trapping in the left lower lobe. A spiral CT scan (fig 1) revealed a multicystic lesion in the posterior basal segment of the left lower lobe supplied by an artery derived from the coeliac axis; venous return to the pulmonary veins was also demonstrated. The presence of the anomalous systemic artery and venous drainage were confirmed by aortography. The patient was asymptomatic and refused surgery.

CASE 2

A 28 year old man presented with a one month history of recurrent haemoptysis. He smoked one pack of cigarettes daily. Chest radiography showed a mass, $4 \mathrm{~cm}$ in diameter, in the right lower lobe. Bronchoscopic examination indicated that the source of bleeding was the right lower lobe but no endobronchial lesions were seen. A spiral CT scan (fig 2) revealed a homogeneous mass in the right lower lobe contigu-
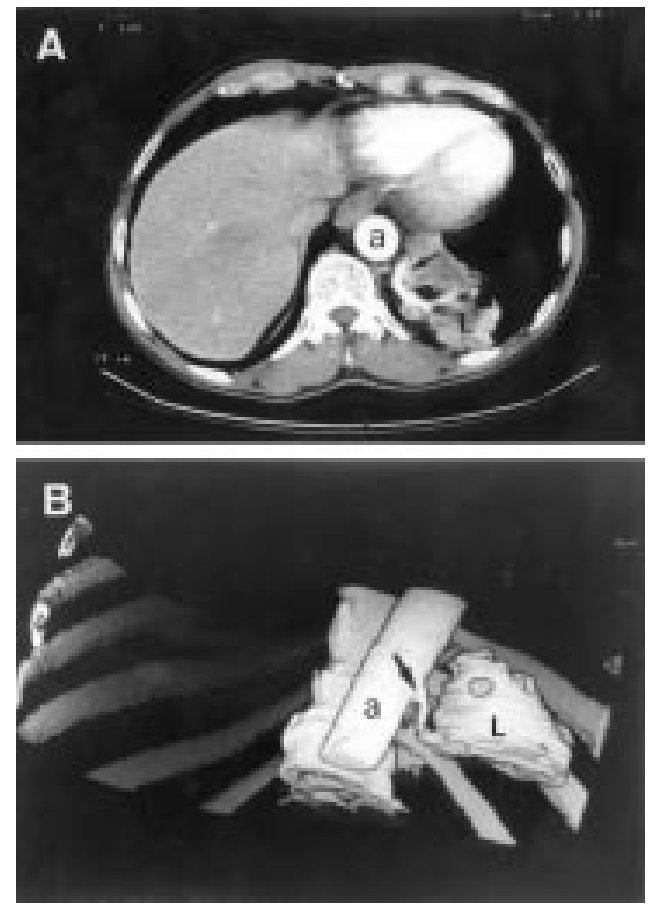

Figure 3 Spiral CT scan of case 3. (A) Contrast enhanced CT axial image showing an anomalous systemic artery (arrow) feeding the pulmonary lesion $(L)$ in the left lower lobe. (B) Left oblique view of helical CT angiogram demonstrating the anomalous artery (arrow) originating from the left wall of the thoracic aorta (a).

ous to the diaphragm and identified its anomalous arterial supply derived from the upper abdominal aorta just above the coeliac artery; venous drainage into the pulmonary veins was also visualised. Intralobar pulmonary sequestration was confirmed by aortography and thoracic surgery.

\section{CASE 3}

A 65 year old male cigarette smoker had a two week history of productive cough and fever. The patient improved with antibiotic therapy but a persistent cough developed. Radiography of the chest showed partial collapse of the left lower lobe and a mass like opacity with an airfluid level. A CT scan demonstrated a non-homogeneous mass with multiple cystic appearing spaces and cavitation involving the posterior basal segment of the left lower lobe. Fibreoptic bronchoscopic examination disclosed no abnormality. A percutaneous fine needle aspiration biopsy specimen of the lesion revealed non-diagnostic findings. Spiral CT angiography (fig 3) showed a feeding systemic artery arising from the descending thoracic aorta and venous drainage to the pulmonary veins. At surgery an infected intralobar sequestration was found.

\section{CASE 4}

A 41 year old man was admitted to hospital with a 48 hour history of fever and pleuritic chest pain. There was no history of use of tobacco. Chest radiography revealed a homogeneous density in the right lower lobe. He was diagnosed as having pneumonia and treated with clarithromycin. One month later he was 

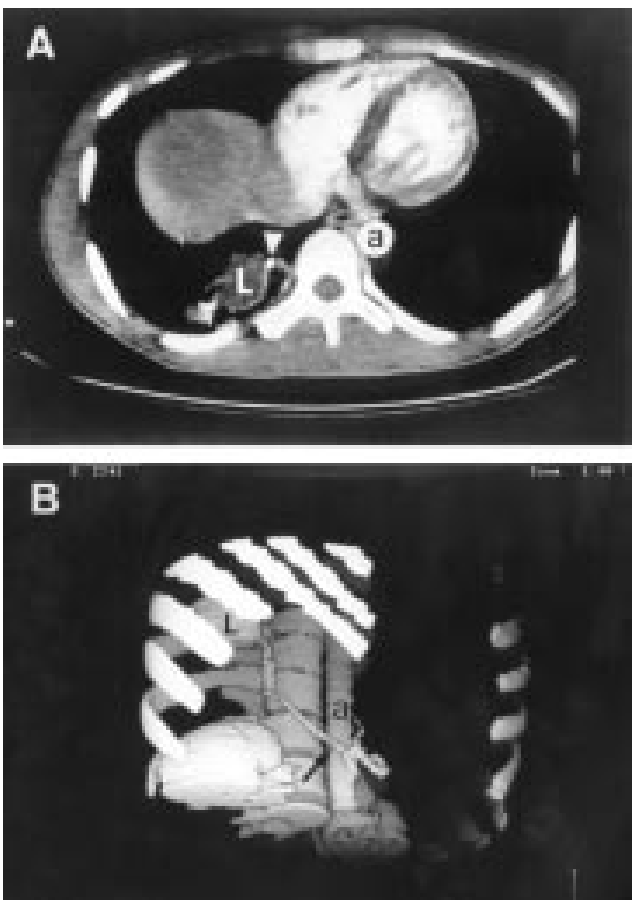

Figure 4 Spiral CT scan of case 4. (A) Contrast enhanced $C T$ axial image showing a systemic artery (arrowhead) feeding the pulmonary lesion $(L)$ in the right lower lobe. (B) Right oblique view of helical CT angiogram showing the anomalous systemic artery (arrow) arising from the coeliac axis. $a=$ aorta.

readmitted with clinical deterioration, unproductive cough, weakness, anorexia, weight loss, and fever. Chest radiography showed a diffuse and bilateral micronodular pattern with persistence of the right lower lobe density. Miliary tuberculosis was confirmed by histopathological examination of a transbronchial biopsy specimen and positive culture of bronchial aspirate. A spiral CT angiogram (fig 4) revealed a focal area of increased density in the right lower lobe supplied by an artery originating from the coeliac axis. An abdominal aortogram showed the anomalous artery and the venous return via the pulmonary veins. Because the lower pulmonary veins were not included in the upper sections of preestablished contrast enhanced helical CT acquisition, in this case spiral CT angiography could not identify the venous drainage. Surgery was not considered at the time this case was presented.

\section{Discussion}

Both intralobar and extralobar sequestration characteristically involves the lower lobes of the lungs. Intralobar pulmonary sequestration accounts for $73 \%$ of all sequestrations and has a predilection for the posterior basal segment of the lower lobes. It occurs slightly more often in the left lung than in the right. ${ }^{2}$ The blind ending bronchi, which may become distended trapping mucus, are prone to infection. In about two thirds of the cases reported the first symptoms occur after the age of 10 years and are usually secondary to a superimposed infection. Productive cough, fever, haemoptysis, recurrent pneumonia, and chest pain are typical presenting complaints. Extralobar se- questrations are frequently discovered during the neonatal period in infants with other congenital anomalies. The clinical picture is usually dominated by the associated anomalies although infection can occur, especially if there is a communication with the oesophagus or the stomach. Extralobar sequestrations that are not diagnosed in newborn infants are often asymptomatic and detected on routine radiography.

In case 1 pulmonary sequestration was detected by routine radiography, while in case 2 haemoptysis was the presenting symptom of an intralobar sequestration. Case 3 had an intralobar sequestration typically manifested by symptoms of infection and case 4 had concomitant disseminated tuberculosis.

Plain radiographs of the chest often show a single homogeneous opacity or, less commonly, a cystic mass in the base of one lung that can sometimes suggest the diagnosis of sequestration. ${ }^{1}$ Less specific findings include recurrent pneumonia and focal bronchiectatic changes. The principal objective for diagnosis of pulmonary sequestration is to identify the systemic artery supply. With this information, imaging can distinguish sequestration from other causes of lung opacity. Because accessory arteries, pleural investment, and venous drainage are adequately determined intraoperatively, at some institutions only the presence and location of an aberrant systemic artery are considered essential for preoperative assessment for any symptomatic pulmonary sequestration. ${ }^{4}$

Imaging strategies for suspected pulmonary sequestration are based on case reports or small series since it is a rare congenital disorder and no study exists that objectively compares imaging techniques for detection, definition, or cost effectiveness. ${ }^{4}$ Since the definitive step in the diagnosis of sequestration is the demonstration of the systemic arterial supply, for a long time diagnosis was made by conventional angiography. More recently all imaging techniques capable of showing the artery have been implicated in evaluating sequestration. Magnetic resonance (MR) imaging and MR angiography can be used together to diagnose pulmonary sequestration in a single noninvasive examination. ${ }^{5}$ Nevertheless, MR cannot accurately evaluate lung parenchyma and the airways and must be considered in terms of cost and availability. Sonography requires a favourable acoustic window and is ideally suited for evaluating the chest prenatally and postnatally. ${ }^{6}$ Other non-invasive techniques for evaluation of sequestration such as scintigraphy are only rarely necessary.

In all four cases described in this report spiral CT angiography successfully delineated the origin and course of the anomalous systemic artery. Axial images were enough to make the diagnosis but three-dimensional reconstruction aided both radiologists and referring clinicians by demonstrating anatomical relationships, particularly for vessels orientated in the $\mathrm{z}$ axis. ${ }^{7}$ On the other hand, venous drainage was also identified in the three cases in which lower pulmonary veins were included in contrast enhanced helical CT scans. We have performed 
three-dimensional reconstruction (3D-SSD) segmentation for a better understanding of the anatomy of the abnormal systemic arteries. However, as shown in case 2, threedimensional imaging dedicated to the venous drainage can also be made. ${ }^{8}$

Spiral CT angiography is a minimally invasive technique for vascular imaging that is made possible by combining slip ring CT scanning and computerised three-dimensional reconstruction. ${ }^{9}$ Spiral CT angiography has several advantages over other non-invasive vascular imaging techniques. ${ }^{40} \mathrm{CT}$ scanning, with its superior spatial resolution, yields the most information about the bronchial anatomy and the pulmonary parenchymal lesion. Sonography and MRI cannot evaluate lung abnormalities accurately although MRI can reveal the cystic nature of many intralobar sequestrations as well as the variable solid, fluid, haemorrhagic, and mucus-containing components. MR angiography is hampered by artefacts caused by respiratory motion whereas this problem is generally avoided in helical CT scanning. CT angiography is less expensive than MR angiography and can be used on patients with a metallic device or who do not tolerate the MR examination. Furthermore, helical CT scanning is faster resulting in less sedation and reduced amount of contrast medium. The disadvantages of helical CT scanning are minor and arise from exposure of the patient to ionising radiation and the administration of intravenous contrast material.

In summary, we report four cases of pulmonary sequestration successfully diagnosed using spiral CT angiography. By allowing simultaneous imaging of anomalous vessels and parenchymal lesions in a single examination, spiral CT angiography is a particularly efficacious technique and has the potential to become the procedure of choice in the diagnosis and assessment of pulmonary sequestration.

1 Felker RE, Tonkin ILD. Imaging of pulmonary sequestration. AfR 1990;154:241-9.

2 Savic B, Birtel FJ, Tholen W, et al. Lung sequestration: report of seven cases and review of 540 published cases. Thorax 1979;34:96-101.

3 Ikezoe J, Muruyama S, Godwin JD, et al. Bronchopulmonary sequestration: CT assessment. Radiology 1990;176: nary 9 .

4 Frush DP, Donnelly LF. Pulmonary sequestration Frush DP, Donnelly LF. Pulmonary sequestration
spectrum: a new spin with helical CT. AfR 1997;169:67982 .

5 Doyle AJ. Demonstration of blood supply to pulmonary sequestration by MR angiography. $A f R$ 1992;158:989-90 6 May DA, Barth RA, Yeager S, et al. Perinatal and postnatal chest sonography. Radiol Clin North Am 1993;31:499-516.

7 Johnson PT, Fischman EK, Duckwall JR, et al. Interactive three-dimensional volume rendering of spiral CT data: current applications in the thorax. Radiographics 1998;18: 165-87.

8 Rémy J, Rémy-Jardin M. Spiral CT angiography of pulmonary vessels. In: Rémy-Jardin M, Rémy J, eds. Spiral CT of the chest. Berlin: Springer-Verlag, 1996: 231-64.

9 Dillon EH, van Leeuwen MS, Fernandez MA, et al. Spiral CT angiography. AfR 1993;160:1273-8.

10 Amitai M, Konen E, Rozenman J, et al. Preoperative evaluation of pulmonary sequestration by helical CT angiography. AfR 1996;167:1069-70.

\section{Thorax 1998;53:1092-1094 Interventricular septal shift due to massive pulmonary embolism shown by CT pulmonary angiography: an old sign revisited \\ Radiology, University Hospital of Wales,} Cardiff, UK

T B Oliver

Department of Radiology, Borders General Hospital, Melrose, UK J H Reid

Department of Clinical Imaging, Royal Infirmary of

Edinburgh, Edinburgh, UK J T Murchison

Correspondence to: Dr JT Murchison, Department of Clinical Imaging, Royal Infirmary of Edinburgh, Lauriston Place, Edinburgh. EH3 9YW, UK.

Received 5 March 1998 Returned to author 13 May 1998

Revised manuscript received

3 July 1998

Accepted for publication

20 August 1998

\section{T B Oliver, J H Reid, J T Murchison}

\begin{abstract}
The computed tomographic (CT) pulmonary angiogram appearances of acute right ventricular dysfunction due to massive pulmonary embolus in a patient are described. Abnormal findings comprised right ventricular dilatation, interventricular septal shift, and compression of the left ventricle. These changes resolved following thrombolysis. Use of CT pulmonary angiography to diagnose pulmonary emboli is increasing. Secondary cardiac effects are established diagnostic features shown by echocardiography. These have not been previously described but are important to recognise as they may carry important prognostic and therapeutic implications.

(Thorax 1998;53:1092-1094)
\end{abstract}

Keywords: pulmonary embolism; right ventricular dysfunction; spiral computed tomography; pulmonary angiography

A 43 year old man collapsed while out walking. On admission to hospital he was dyspnoeic and cyanosed. On direct questioning he admitted to right leg pain. Examination showed that his heart rate was 105 beats/min, respiratory rate was 28 breaths/min, and blood pressure was $100 / 60 \mathrm{~mm} \mathrm{Hg}$. His jugular venous pressure was raised but examination was otherwise normal. Electrocardiography demonstrated sinus tachycardia; the chest radiograph was normal. Measurement of arterial blood gas tensions confirmed hypoxaemia with hypocapnia $\left(\mathrm{PO}_{2}\right.$ $8 \mathrm{kPa}$ on $6 \mathrm{l} / \mathrm{min}$ oxygen, $\left.\mathrm{PCO}_{2} 4 \mathrm{kPa}\right)$. An echocardiogram demonstrated dilatation of the right ventricle. The clinical features of syncope, cyanosis and dyspnoea with engorged neck veins in a patient with a normal chest radiograph and clinical suspicion of deep venous thrombosis led to a presumptive diagnosis of pulmonary embolus.

A computed tomographic (CT) pulmonary angiogram was performed. A $3 \mathrm{~mm}$ spiral scan, reconstructed at $1.5 \mathrm{~mm}$ intervals, was undertaken on a Hi Speed Advantage scanner (General Electric Medical Systems, Milwaukee, Wisconsin, USA) using $150 \mathrm{ml}$ of contrast $(200 \mathrm{mg} \mathrm{I} / \mathrm{ml}$ ) at $4 \mathrm{ml} / \mathrm{s}$. This showed multiple pulmonary emboli within the main and segmental pulmonary arteries. In addition there was dilatation of the right ventricle and atrium with normal wall thicknesses, the interven- 

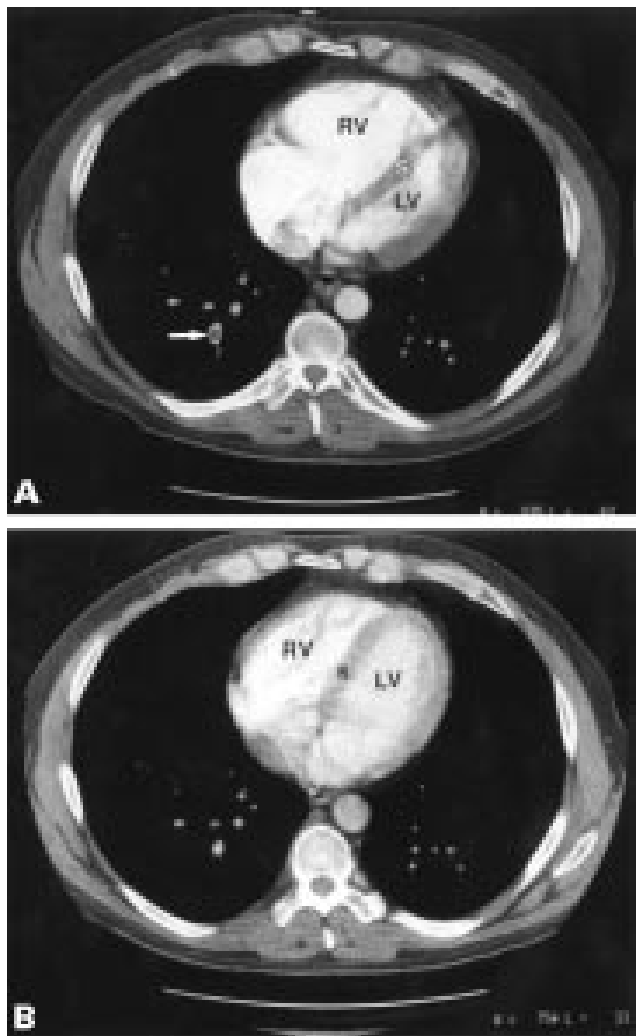

Figure 1 Computed tomographic (CT) pulmonary angiograms at the level of the interventricular septum in a patient with massive pulmonary embolism. (A) The scan at presentation shows right ventricular dilatation and septal displacement which results in compression of the left ventricle. A filling defect due to an embolus is seen within a segmental branch of the descending right pulmonary artery (arrow). (B) Five days after thrombolysis the pulmonary embolus has resolved. The associated reduction in pulmonary artery pressure has allowed normal septal and ventricular appearances to return. The long axis of the heart now occupies a more normal position. $R V=$ right ventricle, $L V=$ left ventricle, $S=$ interventricular septum.

tricular septum was displaced to the left, and there was compression of the left ventricle (fig 1A). These features persisted throughout the cardiac cycle. A central venous catheter was placed and tissue plasminogen activator was infused into the central pulmonary arteries. Immediately before treatment the central venous pressure was $22 \mathrm{~mm} \mathrm{Hg}$, right atrial pressure was $30 \mathrm{~mm} \mathrm{Hg}$, right ventricular pressure was $33 / 13 \mathrm{~mm} \mathrm{Hg}$, and pulmonary artery pressure was $33 / 20 \mathrm{~mm} \mathrm{Hg}$. Five hours after treatment the pulmonary artery pressure had reduced to $20 / 10 \mathrm{~mm} \mathrm{Hg}$ and systemic blood pressure had increased to $160 / 70 \mathrm{~mm}$ $\mathrm{Hg}$. A continuing anticoagulation regime was commenced. A venogram showed thrombus within the right popliteal vein. A repeat CT angiogram five days after treatment showed considerable reduction in the load of embolic material within the pulmonary arteries together with a return of the interventricular septum to its normal position and resumption of normal right and left ventricular morphologies (fig 1B).

\section{Discussion}

Massive pulmonary embolism sets in sequence a chain of physiological events that ultimately lead to reduced systemic cardiac output. ${ }^{1}$ The initial abrupt rise in pulmonary artery pressure causes increased right ventricular afterload which results in right ventricular dilatation and dyskinesia. Secondary effects of this are tricuspid regurgitation, right atrial enlargement, and loss of respiratory variation in calibre of the great veins. Increased right ventricular wall tension may reduce local coronary blood flow, resulting in ischaemia which impairs right ventricular function further. As the right ventricle dilates, the interventricular septum is displaced towards the left ventricle, the right ventricle assuming a circular axial configuration and the left ventricle a crescentic appearance more typical of the normal right ventricle. This septal shift, combined with the constraining influence of the pericardium, results in reduced left ventricular filling which is already compromised by reduced preload. The cardiac output falls.

Signs documenting this sequence such as right ventricular dilatation and hypokinesis (which may spare the apex), abnormal interventricular septal motion, pulmonary artery dilatation, tricuspid regurgitation, and loss in respiratory variation in inferior vena caval diameter can be detected at echocardiography. Echocardiographic assessment of the right ventricle has been recommended as an integral part of the investigative algorithm for suspected acute pulmonary embolus published recently by the British Thoracic Society working party. ${ }^{2}$ "Right ventricular dysfunction" is an umbrella term which also includes more subjective echocardiographic findings such as abnormalities of the motion of the right ventricular wall. These findings are often encountered in lesser degrees of pulmonary embolus and have led to debate over the significance of the more objective signs. Acute right ventricular dilatation and interventricular septal shift have been associated specifically with massive pulmonary embolism $^{34}$ and reversible septal displacement has been described in a series of patients requiring aggressive treatment for circulatory failure due to massive pulmonary embolism. ${ }^{3}$ Thrombolysis is an accepted treatment in massive life threatening pulmonary embolus and its administration in the case described here was associated with a rapid return of pulmonary and systemic arterial pressures towards normal. Recognition of the signs presented by CT scanning or echocardiography allows more aggressive therapy to be targeted to individuals at greatest risk.

CT pulmonary angiography is increasingly used to diagnose pulmonary embolus. It is non-invasive and quick to perform. In the case described the patient was imaged directly after initial assessment in the emergency room and spent less than 15 minutes in the imaging suite. Comparative studies have shown excellent correlation between CT and conventional pulmonary angiography in the detection of emboli in segmental or larger vessels and in many centres the technique has largely replaced conventional pulmonary angiography. ${ }^{56}$ Secondary signs of pulmonary embolus have not, to our knowledge, been described at CT pulmonary angiography. The interventricular septum is usually 
clearly visualised by thoracic CT scanning following intravenous contrast. We have observed interventricular septal shift in several patients with acute pulmonary embolus. Septal shift may also be identified by CT scanning or MRI in patients with chronic pulmonary hypertension due to a variety of causes; however, an important distinguishing feature in such cases is co-existing thickening of the right ventricular wall, which is not observed in acute pulmonary embolus and was not apparent in the case presented here. A typical CT pulmonary angiogram will include in its acquisition time two or three cardiac cycles and some normal variation in the appearance of the cardiac chambers is to be anticipated over the length of the scan. Nevertheless, the constellation of CT findings of proximal emboli, enlargement of the right ventricle with normal wall thickness, interventricular septal shift, and crescentic axial left ventricular morphology which persists throughout the CT scan is likely to be a reliable indication that an embolus of major proportions has occurred.

1 Goldhaber SZ. Pulmonary embolism. In: Braunwald E, ed. Heart disease: a textbook of cardiovascular medicine. Vol 2. 2nd ed. Philadelphia: WB Saunders, 1997: 1582-603.

2 British Thoracic Society, Standards of Care Committee. Suspected acute pulmonary embolism: a practical approach. Thorax 1997;52(Suppl 4).

3 Jardin F, Dubourg O, Gueret P, et al. Quantitative two-dimensional echocardiography in massive pulmonary embolism: emphasis on ventricular interdependence and leftward septal displacement. F Am Coll Cardiol 1987;10: 1201-6.

4 Kasper W, Geibel A, Tiede N, et al. Distinguishing between acute and subacute massive pulmonary embolism by conventional and Doppler echocardiography. Br Heart 7 1993;70:352-6.

5 Blum AG, Delfau F, Grignon B, et al. Spiral computed tomography versus pulmonary angiography in the diagnosis of acute massive pulmonary embolism. Am f Cardiol 1994;74: $96-8$.

6 Remy-Jardin M, Remy J, Deschildre F, et al. Diagnosis of pulmonary embolism with spiral CT: comparison with pulmonary angiography and scintigraphy. Radiology 1996; 200:699-706.

\section{LETTERS TO THE EDITOR}

\section{Cardiac risks with $\beta$ agonists}

Martin $e t$ al ${ }^{1}$ suggest that caution should be exercised when prescribing long acting oral $\beta$ agonists to patients at risk of cardiac failure, based on results from a prescription event monitoring (PEM) study.

Firstly, all $\beta_{2}$ agonists (short and long acting, oral and inhaled) should be used with caution in patients with severe cardiovascular disease, as is pointed out in the package insert for all drugs of this class.

Secondly, the study does not provide any evidence on this issue. PEM studies are not designed to study causal relations but to generate new hypotheses. Although the authors have made an attempt to consider several potential biases in the analyses, the study design is inappropriate compared with, for example, a prospective randomised controlled trial, and the results must be interpreted with great caution.

Thirdly, no support for an association between bambuterol and an increased risk for cardiac failure has been found in our review of preclinical studies, clinical studies (including >3000 patients/healthy volunteers), or post-marketing surveillance (based on $>130$ million treatment days)

Fourthly, according to the authors there have been no spontaneous reports of cardiac failure with bambuterol to the Committee on Safety of Medicines. This is in agreement with the WHO database Intdis, with no reports of cardiac failure for bambuterol.

Finally, the paper suggests a doubled asthma mortality in patients receiving salmeterol. In our opinion the reported higher relative risk for non-fatal cardiac failure for bambuterol and the doubled asthma mortality for salmeterol both appear equally explicable by factors other than direct causality, such as confounding by concomitant diseases and disease severity.

Thus, PEM data may be of help in identifying signals with new drugs, but there is little if any merit in comparing drugs used in different populations and introduced to the market at different times.

Table 1 Rates of cardiac failure during the first month of exposure to bambuterol or a cardiovascular drug studied by prescription event monitoring (PEM)

\begin{tabular}{llllll}
\hline Drug* (ranked & $\begin{array}{l}\text { No. of patients with } \\
\text { reported cardiac failure } \\
\text { during month 1 }\end{array}$ & $\begin{array}{l}\text { No. of } \\
\text { patient-months } \\
\text { of exposure } \\
\text { during month 1 }\end{array}$ & $\begin{array}{l}\text { Rate (events per } \\
\text { 1000 months of } \\
\text { exposure) }\end{array}$ & $\begin{array}{l}\text { Mean (SD) } \\
\text { age }\end{array}$ & Males (\%) \\
\hline Xamoterol & 97 & 4463 & 21.7 & $70.8(13.9)$ & 53.0 \\
Nicorandil & 73 & 11578 & 6.3 & $66.9(11.2)$ & 61.1 \\
Bambuterol & 29 & 5891 & 4.9 & $58.5(18.6)$ & 44.8 \\
Losartan & 53 & 12990 & 4.1 & $63.5(12.1)$ & 40.2 \\
Diltiazem & 24 & 8808 & 2.7 & $62.3(13.9)$ & 59.3 \\
Enalapril & 33 & 13544 & 2.4 & $61.2(14.9)$ & 46.1 \\
Perindopril & 17 & 8368 & 2.0 & $61.8(12.7)$ & 45.0 \\
Nicardipine & 17 & 9517 & 1.8 & $62.9(13.9)$ & 48.4 \\
Lisinopril & 18 & 11574 & 1.6 & $60.9(14.3)$ & 44.0 \\
Ramipril & 2 & 1277 & 1.6 & $60.5(12.4)$ & 45.1 \\
Amlodipine & 12 & 12085 & 1.0 & $61.8(14.7)$ & 46.9 \\
\hline
\end{tabular}

${ }^{\star}$ Betaxolol, doxazosin, isradipine not shown as number of patients with event was $<2$, or rate was $<1.0$ per 1000 patient-months of exposure.
BERTIL LINDMARK Department of Clinical Drug Safety and Epidemiology, Clinical RED, Astra Draco, S221 00 Lund, Sweden

1 Martin RM, Dunn NR, Freemantle SN, et al. The risk of non-fatal cardiac failure and ischemic heart disease with long acting $\beta_{2}$ agonists. Thorax 1998;53:558-62.

AUTHORS' REPLY Bertil Lindmark of Astra Draco makes five points about our study on the risk of non-fatal cardiac failure and ischaemic heart disease with long acting $\beta_{2}$ agonists. Firstly, he points out that all $\beta_{2}$ agonists should be used with caution in patients with severe cardiovascular disease. The cardiac effects of $\beta_{2}$ agonists are well described, but there is limited evidence available on whether or not the risks of adverse cardiac effects differ depending on the dose and method of administration of the drug. Clearly, these are important questions for prescribing doctors faced with treating asthmatic patients with concomitant cardiac disease. An observational cohort study formed from health insurance databases from the Province of Saskatchewan, Canada found an increased relative risk of death from cardiovascular disease in users of $\beta_{2}$ agonists taken orally or by nebuliser, but not in users of $\beta_{2}$ agonists administered by metered dose inhaler. ${ }^{2}$ The deaths occurred in patients with significant cardiac disease, suggesting that $\beta_{2}$ agonists taken orally or by nebuliser should be avoided in patients at high risk of cardiovascular events. We found that the oral $\beta_{2}$ agonist bambuterol, but not the inhaled $\beta_{2}$ agonist salmeterol, was associated with an increased risk of non-fatal cardiac failure. The results from both these studies are plausible as oral $\beta$ agonists provide a greater systemic dose than that achieved with metered dose inhalers ${ }^{1}$ and tachycardia and prolonged Q-T interval have been reported principally with nebulised or oral $\beta$ agonists. ${ }^{2}$ The advised total daily dose of oral bambuterol 
(20 mg) is 200 times that of inhaled salmeterol $(100 \mu \mathrm{g}) .^{3}$

Secondly, Dr Lindmark reiterates our point that the results must be interpreted with caution because the study was observational, and more definitive evidence would come from a prospective randomised trial. Nevertheless, hypotheses about drug safety concerns are often generated from observational studies. ${ }^{4}$ Such studies drive further research because they provide an "a priori" hypothesis and allow the formulation of a clinically relevant end point. Until results from prospective trials become available, observational research using cohort or case-control techniques remains an important source of evidence about the safety of drugs.

Thirdly, he states that a review by Astra Draco has found no evidence from premarketing or post-marketing studies of an association between bambuterol and cardiac failure. In general, pre-marketing studies have their own limitations, ${ }^{5}$ as evidenced by the recent withdrawal on safety grounds of two newly launched drugs. ${ }^{6}$ Similarly, different types of post-marketing surveillance studies, including PEM, have different advantages and disadvantages and, in general, one system cannot be relied upon to provide all the evidence needed. ${ }^{7}$ This point also applies in response to the fourth comment. In particular, it should be noted that there is gross under-reporting of suspected adverse drug reactions to the Committee on Safety of Medicines $^{8}$ and other regulatory authorities, and there are many difficulties associated with interpreting data from spontaneous reporting schemes. ${ }^{5}$

Finally, as is stated clearly in our paper, it is possible that the association may be explained by factors such as confounding by concomitant disease and disease severity. Interestingly, the rate of cardiac failure associated with bambuterol in the first month of treatment was higher than for 11 cardiovascular drugs previously studied by PEM (table 1). Only two cardiac drugs, including the inotropic sympathomimetic xamoterol (licensed for use in mild heart failure) had higher rates of cardiac failure. Since it is highly unlikely that the rate of cardiovascular disease in the bambuterol cohort was higher than in cohorts of patients taking cardiac drugs, and the bambuterol cohort was the youngest, these data provide further evidence that an association cannot be discounted. Our findings require confirmation, but we remain concerned about the size and biological plausibility of the association.

RICHARD M MARTIN
NICHOLAS R DUNN
RONALD D MANN
SHAYNE N FREEMANTLE
Drug Safety Research Unit,
Bursledon Hall,
Blundell Lane,
UK

1 Nelson HS. $\beta$-adrenergic bronchodilators. $N$ Engl F Med 1995;333:499-506.

2 Suissa S, Hemmelgarn B, Blais L, et al. Bronchodilators and acute cardiac death. $A m^{\mathcal{F}}$ Respir Crit Care Med 1996;154:1598-602.

3 Joint Formulary Committee. British National Formulary Number 33. London: British Medical Association and Royal Pharmaceutical Society of Great Britain, 1997:125-6.

4 Olsen JH. Interpretation in drug epidemiology. Lancet 1998;352:162-3.

5 Waller PC, Coulson RA, Wood SM. Regulatory pharmacovigilance in the United Kingdom: current principles and practice. Phar
miol Drug Safety 1996;5:363-75.
$6 \mathrm{Li}$ Wan Po A, Zhang WY. What lessons can be learnt from withdrawal of mibefradil from the learnt from withdrawal of mibefradil
market? Lancet 1998;351:1829-30.

7 Lawson DH. Pharmacovigilance in the 1990s. Br f Clin Pharmacol 1997;44:109-10.

8 Martin RM, Kapoor KV, et al. Underreporting of adverse drug reactions to newly marketed, black triangle drugs in general practice in England: observational study. BMf 1998;317: 119-20.

\section{Genetics and tuberculosis}

Dr Richard Bellamy alludes to the important fact, frequently ignored by immunologists, geneticists and epidemiologists, that tuberculosis has several different clinical forms. ${ }^{1}$ Physicians have emphasised the difference between primary tuberculosis, which is comparable to Lurie's susceptible rabbits with disseminated disease, and post primary tuberculosis, best characterised by smear positive pulmonary tuberculosis and Lurie's "resistant" rabbits. HLA associations with tuberculosis have indeed been inconsistent when all forms of tuberculosis are included. However, the HLA association with DR2, and particularly with its subtype DR15 in linkage disequilibrium with DQ5, was found only in patients with smear positive pulmonary tuberculosis. ${ }^{23}$ These observations have been refined using DNA based HLA typing and have confirmed a link with the genes $D R B 1^{\star} 1501$ and $D Q B 1{ }^{\star} 0502 .{ }^{4}$ Antibody levels to epitopes of the $38 \mathrm{kDa}$ antigen of $\mathrm{Myco}-$ bacterium tuberculosis restricted antigens were higher, suggesting an enhanced immune responsiveness in those with HLA-DR $15 .{ }^{3}$

The relative importance of the genes involved in susceptibility can be assessed by the gene frequency, but also by the attributable riskthat is, how much of the disease can be attributed to the presence or absence of a particular gene $34 \%$ with $95 \%$ confidence intervals of 16 to $43 \%$ were suggested for DR15 in one population ${ }^{3}$ )

The Lurie experiment suggests that a comparison between patients with different forms of tuberculosis, matched by ethnic origin, may be valuable in identifying candidate genes for susceptibility to tuberculosis. Since smear positive pulmonary tuberculosis is responsible for transmission of the disease, an understanding of its pathogenesis will be especially important in finding new ways to control tuberculosis.

GRAHAM H BOTHAMLEY East London Tuberculosis Service, Homerton Hospital, London E9 6SR, UK

1 Bellamy R. Genetic susceptibility to tuberculosis in human populations. Thorax 1998;53:58893.

2 Brahmajothi V, Pitchappan RM, Kakkanaiah $\mathrm{VN}$, et al. Association of pulmonary tuberculosis and HLA in South India. Tubercle 1991;72: 123-32.

3 Bothamley GH, Schreuder GMT. Human leukocyte antigen, tuberculosis and Mycobacterium tuberculosis-specific antibody. F Infect Dis rium tuberculo

4 Meyer CG, May J, Stark K. Human leukocyte antigens in tuberculosis and leprosy. Trends Microbiol 1998;6:148-54.

\section{Chlamydia pneumoniae and asthma}

The paper by Cook et al examines the possible association between Chlamydia pneumoniae infection and asthma. The authors conclude that their data do not support this association. However, we feel that the sero- logical tests performed give important information on the prevalence of infection, but are not sufficiently complete to make definitive conclusions on the incidence of acute $C$ pneumoniae infection in the populations under study. The major pitfall in the study, as pointed out by the authors, is the small proportion of patients from whom a convalescent serum sample was drawn. Moreover, the arbitrary exclusion of $\operatorname{IgM}$ positive patients for the diagnosis of acute $C$ pneumoniae infection may have been misleading since the possibility of cross reactivity with rheumatoid factor could have been effectively ruled out by using IgG absorption prior to IgM microimmunofluorescence determination. ${ }^{2}$ Notwithstanding these facts, the authors conclude that the study does not support "an association between $C$ pneumoniae antibody titres and the incidence of acute asthma attacks".

Analysis of table 1 indicates that the acute asthma and control populations appear to be significantly different in terms of age and sex distribution, the control population being significantly older and showing a male predominance. Both these factors are associated with increased $C$ pneumoniae incidence and prevalence. The authors report using a logistic regression modelling method in which the age value is implemented as " \pm 10 years", which is roughly equivalent to the difference in mean age between the acute asthma and control populations.

This study is certainly noteworthy in that it underlines an association between $C$ pneumoniae infection and severe chronic asthma, particularly "brittle" asthma, which will require further investigation in the future.

$$
\begin{array}{r}
\text { FRANCESCO BLASI } \\
\text { LUIGI ALLEGRA } \\
\text { PAOLO TARSIA } \\
\text { Istituto di Tisiologia e Malattie dell'Apparato } \\
\text { Respiratorio, } \\
\text { Università degli Studi di Milano, } \\
\text { Pad. Litta, } \\
\text { IRCCS Ospedale Maggiore di Milano, } \\
\text { Italy }
\end{array}
$$

1 Cook PJ, Davies P, Tunnicliffe W, et al. Chlamydia pneumoniae and asthma. Thorax dia p98;53:254-9.

2 Verkooyen RP, Hazemberg MA, Van Haaren $\mathrm{GH}$, et al. Age-related interference with Chlamydia pneumoniae microimmunofluorescence serology due to circulating rheumatoid factor. $\mathcal{f}$ rology due to circulating rheum
Clin Microbiol 1992;30:1287-90.

\section{Chlamydia pneumoniae and asthma}

I read with interest the recent report by Cook et $a l^{1}$ in which they report that, compared with hospital controls, outpatients with chronic severe asthma had significantly more C pneumoniae antibody titres (IgG 64-256 and/or IgA $\geqslant 8$ ) indicating previous infection, whereas unselected patients admitted to hospital for acute asthma attacks had titres similar to controls. They also found that serological evidence of acute (re)infection (presence of IgM, a fourfold change in titre, and/or IgG titre $\geqslant 1: 512$ ) was equal among groups.

These data are in accord with previous evidence suggesting an important role for chronic $C$ pneumoniae infection as a promoter of asthma symptoms but a lesser role for acute infection as a cause for asthma exacerbations. ${ }^{2}$ An additional recent report of positive therapeutic responses to antibiotics 
in severe steroid dependent asthmatic patients (aged 13-65) further supports the possibility that antibody titres indicative of "previous infection" may also indicate persistent chronic infection. ${ }^{3}$

Acute primary (presence of $\operatorname{Ig} M$ ) or secondary (fourfold change in titre without $\operatorname{IgM}$ ) $C$ pneumoniae infection has been reported to initiate asthma in previously non-asthmatic individuals. ${ }^{4}$ Since the incidence of asthma in adults is very small (around one per 1000 per year) it is likely that most of the acute exacerbations occurred in patients who had had previous wheezing episodes. It would be interesting to know whether Cook et al can retrospectively identify any patients who had their very first wheezing episode; this might be easier in general practice than in a hospita based study.

\section{DAVID L HAHN Arcand Park Clinic, Dean Medical Center 3434 E Washington Avenue, Madison, WI 53704, USA}

1 Cook PJ, Davies P, Tunnicliffe W, et al. Chlamydia pneumoniae and asthma. Thorax 1998;53:254-9.

2 Hahn DL. Intracellular pathogens and their role in asthma: Chlamydia pneumoniae in adult in asthma: Chlamydia pneumoniae in

3 Hahn D, Bukstein D, Luskin A, et al. Evidence for Chlamydia pneumoniae infection in steroiddependent asthma. Ann Allergy Asthma Immunol 1998;80:45-9.

$4 \mathrm{Hahn}$ D. Incident wheezing and prevalen asthma have different serologic patterns of "acute" Chlamydia pneumoniae antibodies in adults. Proceedings of the Third Meeting of the European Society for Chlamydia Research, Vienna, Austria. Bologna: Società Editrice Esculapio, 1996: 226.

\section{Non-Hodgkin's lymphoma with CFA}

We read with interest the case report by Orchard et al on non-Hodgkin's lymphoma arising in cryptogenic fibrosing alveolitis (CFA). ${ }^{1}$ Although the authors state that this has not been described previously, we recently reported six cases of pulmonary B cell non-Hodgkin's lymphomas arising in patients with autoimmune disorders, three of whom had CFA. ${ }^{2}$ As in the case described by Orchard et al, prognosis in these three patients was much poorer than that in the patients with high grade pulmonary nonHodgkin's lymphomas unassociated with CFA, presumably due to the combined effects of the two diseases. BRYAN CORRIN Department of Histopathology, Royal Brompton Hospital, Sydney Street, London SW3 6NP

1 Orchard TR, Eraut CD, Davison AG. NonHodgkin's lymphoma arising in cryptogenic fibrosing alveolitis. Thorax 1998;53:228-9.

2 Nicholson AG, Wotherspoon AC, Jones AL, et al. Pulmonary B-cell non-Hodgkin's lymphoma associated with autoimmune disorders: a clinicopathological review of six cases. Eur Respir F 1996;9:2022-5.

AUTHOR's REPLY We are grateful to Dr Nicholson and Professor Corrin for pointing out their very interesting report, which was published after the original writing of our case report.
In the patient we reported the association was with cryptogenic fibrosing alveolitis (CFA) alone whereas, interestingly, the three patients they report had CFA associated with fact that CFA alone may be associated with $B$ cell lymphomas, and the poorer prognosis seen by Nicholson and Corrin in their patients, as well as ours, supports the hypothesis that chronic local stimulation of the lymphoid system may play an important part in the aetiology and prognosis of these tumours.

T R ORCHARD

C D ERAUT A G DAVISON Southend Hospital, Westcliff on Sea, Essex SSO ORY,

\section{BOOK REVIEWS}

Respiratory Measurement. Göran Hedenstierna. (Pp 184, paperback; £19.95 (UK), 1998. ISBN 0727912070.

A large amount of information has been packed into the 184 pages of this new guidebook in the Principles and Practice Series. This is a comprehensive review of the principles of ventilation and gas exchange with special emphasis on the application of pulmonary function measurement during anaesthesia. The book details physiological principles and gives practical measurement guidance, with common sources of error, in the normal circumstances and during anaesthesia. The content is concise, the style direct and occasionally hard going. The text is clear and the diagrams are worth a special mention for their clarity and simplicity. This is not a textbook for beginners and requires a moderate familiarity with the principles of respiratory physiology, and the rules which govern respiratory mechanics and gas measurement. This guide represents excellent value for money and would be equally at home in the pulmonary function laboratory as well as the anaesthetics department. - SR

Asthma: Basic Mechanisms and Clinical Management. 3rd Edition. Barnes PJ, Rodger IW, Thomson NC, eds. other systemic autoimmune disorders. The $£ 22.00$ (overseas)). London: BMJ Books,

(Pp 942; hardback; \$150.00). London: Academic Press, 1998. 0120790270.

This is the third edition of an established book. Aiming to bring together all the recent information on basic mechanisms of asthma and also cover clinical aspects and therapy in depth, this is achieved successfully. The scope of the book provides accessible reviews of all facets of asthma, from epidemiology and physiology to allergen avoidance, including recent developments in these fields. Modifications to the popular second edition include separate chapters on mediator antagonists and immunomodulators with consideration of the potential therapeutic benefits of intervening in the complex inflammatory and pharmacological pathways systematically covered in previous chapters. A new chapter on the pharmacoeconomics of asthma treatments provides a pertinent reminder that, after the wonders of basic science and the development of beneficial interventions, a wider perspective is required to successfully deliver benefits to those who require them. The addition of colour plates provides a welcome change to the previous black and white prints of the old edition which look a little drab in retrospect.

Well written by authorities in their fields and uniformly edited with an attractive presentation, this is an excellent book which succeeds in linking the rapidly developing body of knowledge on asthma with current treatment, while keeping the future constantly in mind.-AF

\section{CORRECTION}

\section{Clinical features of non-smokers with $\alpha_{1}$-antitrypsin deficiency}

The authors of the paper entitled "Clinical features and prognosis of life time nonsmokers with severe $\alpha_{1}$-antitrypsin deficiency" by N Seersholm and A Kok-Jensen, which appeared on pages $265-8$ of the April issue of Thorax, regret that some errors occurred in the text and in table 3. On page 267 the first line of column 1 should have read: ". . . 50 years at entry was $\mathbf{5 6 \%}$ compared with $\mathbf{5 0 \%}$ for the subjects over 50 years ...". Table 3 is reproduced here with the corrections shown in bold italics.

Table 3 Mean (SD) $F E V_{1} \%$ predicted and $F E V_{1} / F V C$ of index and non-index cases stratified by age at entry

\begin{tabular}{|c|c|c|c|}
\hline & Index cases & Non-index cases & $\begin{array}{l}p \text { value } \\
\text { (t test) }\end{array}$ \\
\hline All age groups & $\mathrm{n}=27$ & $\mathrm{n}=40$ & \\
\hline $\mathrm{FEV}_{1}$ (\% predicted) & $54(25)$ & $100(21)$ & $<0.001$ \\
\hline $\mathrm{FEV}_{1} / \mathrm{FVC}$ & $0.57(0.18)$ & $0.79(0.13)$ & $<0.001$ \\
\hline $\mathrm{N}(\%)$ with $\mathrm{FEV}_{1} \%$ pred $\leqslant 70 \%$ & $20(74 \%)$ & $3(8 \%)$ & $<0.001$ \\
\hline Age at entry $<50$ years & $\mathrm{n}=8$ & $\mathrm{n}=26$ & \\
\hline $\mathrm{FEV}_{1}(\%$ predicted $)$ & $56(37)$ & $100(19)$ & $<0.001$ \\
\hline $\mathrm{FEV}_{1} / \mathrm{FVC}$ & $0.53(0.20)$ & $0.80(0.12)$ & $<0.001$ \\
\hline $\mathrm{N}(\%)$ with $\mathrm{FEV}_{1} \%$ pred $\leqslant 70 \%$ & $4(50 \%)$ & $2(8 \%)$ & $<0.001$ \\
\hline Age at entry $\geqslant 50$ years & $\mathrm{n}=19$ & $\mathrm{n}=14$ & \\
\hline $\mathrm{FEV}_{1}$ (\% predicted) & $50(20)$ & $101(24)$ & $<0.001$ \\
\hline $\mathrm{FEV}_{1} / \mathrm{FVC}$ & $0.58(0.17)$ & $0.78(0.14)$ & $<0.001$ \\
\hline $\mathrm{N}(\%)$ with $\mathrm{FEV} \%$ pred $\leqslant 70 \%$ & $16(84 \%)$ & $1(7 \%)$ & $<0.001$ \\
\hline
\end{tabular}

